\title{
Spatial and Temporal Features of Heat Stroke Mortality in Japan and Their Relation to Temperature Variations, 1999-2014
}

\author{
FUJIBE Fumiaki*, MATSUMOTO Jun** and SUZUKI Hideto*** \\ * Research Center for Climatology, Department of Geography, Tokyo Metropolitan University; 1-1 Minami-Osawa, Hachioji, Tokyo \\ 192-0397, Japan. \\ ** Research Center for Climatology, Department of Geography, Tokyo Metropolitan University; 1-1 Minami-Osawa, Hachioji, Tokyo \\ 192-0397, Japan. \\ ***Tokyo Medical Examiner's Office; 4-21-18 Otsuka, Bunkyo, Tokyo 112-0012, Japan. \\ E-mail:ffujibe.bs@gmail.com*
}

Received July 22, 2017; Accepted January 30, 2018

\begin{abstract}
Regional and seasonal features and the interannual variations of heat stroke mortality in Japan are examined using the Vital Statistics of Japan from 1999 to 2014. We found that heat stroke mortality has different spatial patterns and different dependence on temperature, according to age groups. For the age group under 60 , mortality is positively correlated with seasonal mean temperature and is higher in the southern regions of Japan, while the mortality of the age group 80 and over is positively correlated with summer peak temperature, being high in some prefectures in northern to central Honshu, the main island of Japan. The latter group also shows larger interannual variations and a higher increasing trend than the former. As for seasonal variation, heat stroke mortality is high in July-August, with a peak period delay northward, which corresponds to a later temperature peak. Moreover, mortality tends to be higher in July than August by $40-50 \%$ even if the monthly mean temperature is equal. These findings are expected to provide a statistical basis to cope with heat load disasters in Japan.
\end{abstract}

Key words heat stroke mortality, vital statistics, temperature

\section{Introduction}

In Japan, deaths from excessive heat number from several hundred to over a thousand people yearly. Fujibe (2013) examined the change in heat stroke deaths from 1909 to 2011 using data from the Vital Statistics compiled by the Government of Japan, and showed an increase in mortality over the recent few decades, especially for elderly people. He also showed a positive correlation between the year-to-year variations of summer temperature and heat mortality, with increases by $40-60 \%$ for a $1^{\circ} \mathrm{C}$ temperature increment. However, published data on heat stroke deaths in the Vital Statistics are limited to annual totals over the country, with categorization by age and gender, or a total over ages by prefecture, making it difficult to detail geographical and climatological features.

Hoshi et al. (2010) collected individual data from the Vital Statistics of Japan for 33 years (1975 to 2007, 5,877 cases), and investigated the distribution and variation of heat mortality. They showed that prefecture-averaged heat mortality was highest in Okinawa, the southernmost prefecture, and lowest in Hokkaido, the northernmost island, with a statistically significant correlation between mortality and annual highest temperature. However, their description of the regional features of mortality and their dependence on temperature was largely qualitative, and seasonal features were not described. Miyatake et al. (2012) and Murakami et al. (2012) examined the relationship between the ambulance transports of heat-stroke patients and temperature for each prefecture, but their analysis was confined to a single month each, August 2009 and August 2010, respectively.

Recently, Hoshi et al. (2016) analyzed the dependence of the heat disorder-related mortality rate on temperature in seven large cities in Japan over 13 years (1995-2007), based on 4,126 observations. They showed that heat disorder-related mortality in two cities in northern Japan (Sapporo and Sendai) starts to increase at a lower temperature than in the other five cities in the southern regions, implying lower tolerance of the dwellers in cooler climates to the heat load. However, limited details are available about the spatial and temporal temperature variations of heat stroke deaths.

The purpose of this present study is to obtain quantitative information of the regional and seasonal features of heat mortality, and their relationship to temperature in 


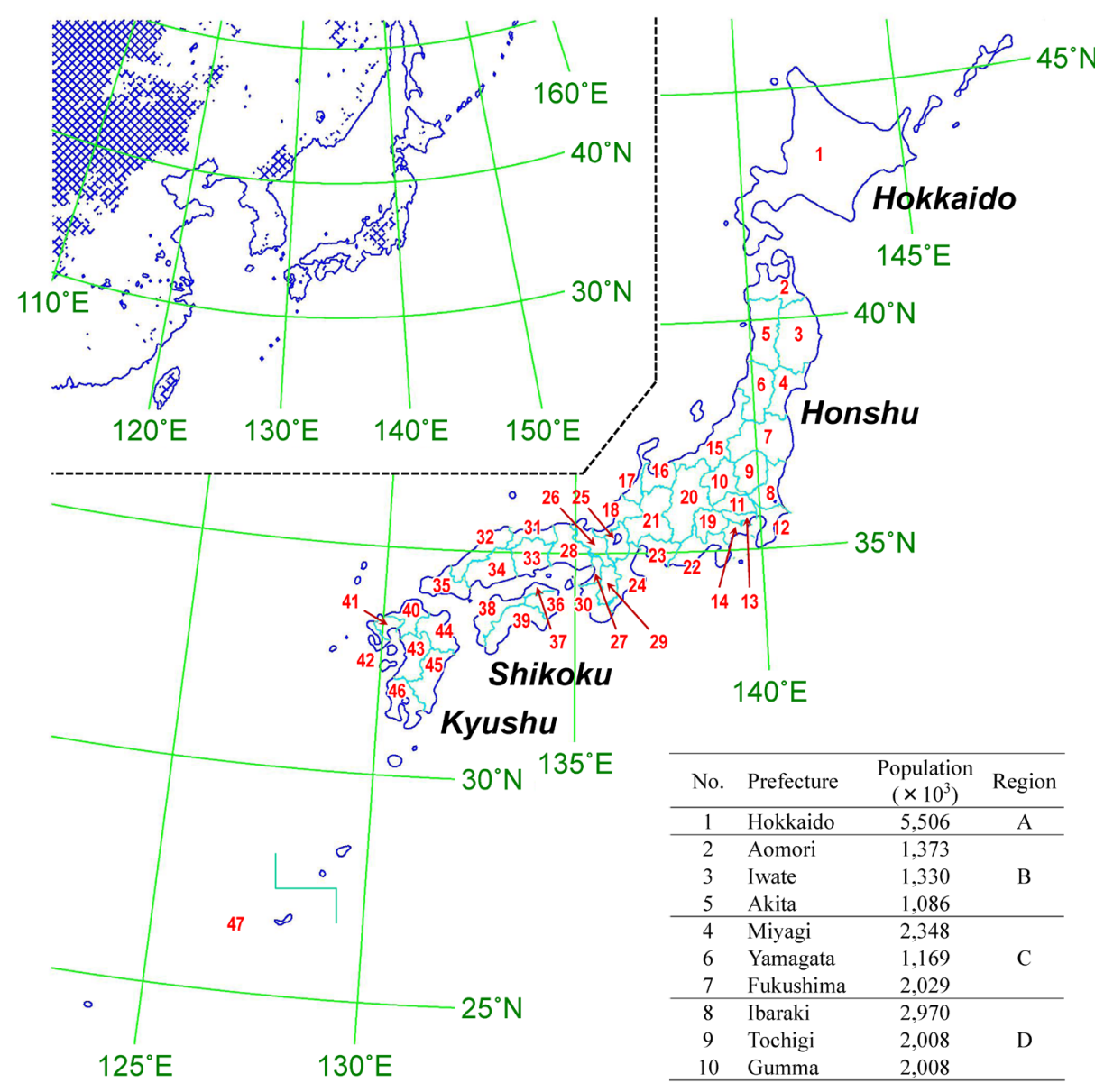

\begin{tabular}{clcc}
\hline No. & Prefecture & $\begin{array}{c}\text { Population } \\
\left(\times 10^{3}\right)\end{array}$ & Region \\
\hline 11 & Saitama & 7,195 & \\
12 & Chiba & 6,216 & $\mathrm{E}$ \\
13 & Tokyo & 13,159 & \\
14 & Kanagawa & 9,048 & \\
\hline 15 & Niigata & 2,374 & \\
16 & Toyama & 1,093 & $\mathrm{~F}$ \\
17 & Ishikawa & 1,170 & \\
18 & Fukui & 806 & \\
\hline 19 & Yamanashi & 863 & $\mathrm{G}$ \\
20 & Nagano & 2,152 & \\
\hline 21 & Gifu & 2,081 & \\
22 & Shizuoka & 3,765 & $\mathrm{H}$ \\
23 & Aichi & 7,411 & \\
24 & Mie & 1,855 & \\
\hline 25 & Shiga & 1,411 & \\
26 & Kyoto & 2,636 & \\
27 & Osaka & 8,865 & $\mathrm{I}$ \\
28 & Hyogo & 5,588 & \\
29 & Nara & 1,401 & \\
30 & Wakayama & 1,002 & \\
\hline 31 & Tottori & 589 & \\
32 & Shimane & 717 & \\
33 & Okayama & 1,945 & $\mathrm{~J}$ \\
34 & Hiroshima & 2,861 & \\
35 & Yamaguchi & 1,451 & \\
\hline 36 & Tokushima & 785 & \\
37 & Kagawa & 996 & $\mathrm{~K}$ \\
38 & Ehime & 1,431 & \\
39 & Kochi & 764 & \\
\hline 40 & Fukuoka & 5,072 & \\
41 & Saga & 850 & \\
42 & Nagasaki & 1,427 & $\mathrm{~L}$ \\
43 & Kumamoto & 1,817 & \\
44 & Oita & 1,197 & \\
\hline 45 & Miyazaki & 1,135 & $\mathrm{M}$ \\
46 & Kagoshima & 1,706 & $\mathrm{~N}$ \\
\hline 47 & Okinawa & 1,393 & \\
& & & \\
& & & \\
\hline
\end{tabular}

Figure 1. Topography of East Asia, with shading for areas above $1,000 \mathrm{~m}$ from the mean sea level (upper left), and prefectures of Japan (center). The list of prefectures is shown on the right-hand side.

Japan. For this purpose, individual data from the Vital Statistics were collected for 1999-2014 and statistically analyzed.

\section{Data and Methodology}

\section{Heat stroke deaths}

The death statistics in the Vital Statistics of the Ministry of Health, Labour and Welfare of Japan (MHLW) are based on the International Classification of Diseases (ICD, http://www.who.int/classifications/icd/ en/). Since 1995, the tenth version of ICD (ICD10) has been used. For this study, individual data on deaths due to "exposure to excessive natural heat," with ICD code X30, were obtained from the MHLW from 1999 to 2014. There are 9,280 cases with information of gender, age, date, and place of death. Among them, 81 cases were not used because the place of death was unknown or outside Japan. Moreover, there are some cases in cold seasons with considerably low temperatures, including a few cases at temperatures below $0^{\circ} \mathrm{C}$. These may correspond to unusual situations such as death during bathing. To focus on deaths as a result of a hot climate, the analysis period included the four months from June to September, except the analysis of seasonal changes. The number of cases over these months is 8,698 , namely, $94.6 \%$ of the total 9,199 . The subsequent analysis is based on totals for each prefecture, age group, and year or month. Figure 1 shows the map of Japan, with all 47 prefectures.

\section{Population and mortality}

Mortality calculations were made using population data categorized by age and prefecture. They were obtained from the reports of the National Census of Japan in 2000, 2005, 2010, and 2015, and interpolated to each year using a cubic function.

The age-specific mortality of an age category $k$ in prefecture $i$ and year $n$ is defined by

$$
m_{k i n}=\frac{d_{k i n}}{p_{k i n}}
$$

where $m_{k i n}, d_{k i n}$, and $p_{k i n}$ are mortality rate, number of deaths, and population of category $k$ in prefecture $i$ and year $n$, respectively. Age categories were defined over five-year intervals, as $0-4,5-9, \ldots, 95-99$, and above 100 years. 
In the subsequent analysis, $M_{\text {in }}$ is defined as mortality for a region consisting of more than one prefecture (A to $\mathrm{N}$ in Figure 1), where suffix $i$ indicates the region.

For an age group that spans over more than one of the five-year age categories, the crude mortality rate can be defined by

$$
M_{i n}^{*}=\frac{\sum_{k} d_{k i n}}{\sum_{k} p_{k i n}},
$$

where the sum is over the considered age categories. However, $M^{*}$ is affected by the age distribution, which is different by region and year. The age-standardized mortality rate is defined by normalizing the population as

$$
M_{i n}=\frac{\sum_{k} d_{k i n}\left(P_{k} / p_{k i n}\right)}{\sum_{k} P_{k}}=\frac{\sum_{k} m_{k i n} P_{k}}{\sum_{k} P_{k}},
$$

where $P_{k}$ is the population of category $k$ in the reference region and year, which has been set to 1985 as per the official statistics of the MHLW. In our study, however, $P_{k}$ is set to the population of the entire country in 2010, in view of the rapid population aging that accounts for most heat stroke casualties.

Mortality is expressed as an annual value, even if defined for a limited period of the year. For example, the mortality for June to September is calculated from Eqs. (1) and (3) by considering the number of fatalities in these four months as an annual value.

Figure 2 shows the number of heat stroke deaths and mortality of the entire country for all age ranges. The number of deaths is highest for age range $80-84$, while mortality increases almost linearly up to 100 years old. Since mortality is scaled in logarithm in Figure 2, linear dependence indicates an exponential increase with age. It has also been found that heat mortality has an exponen-
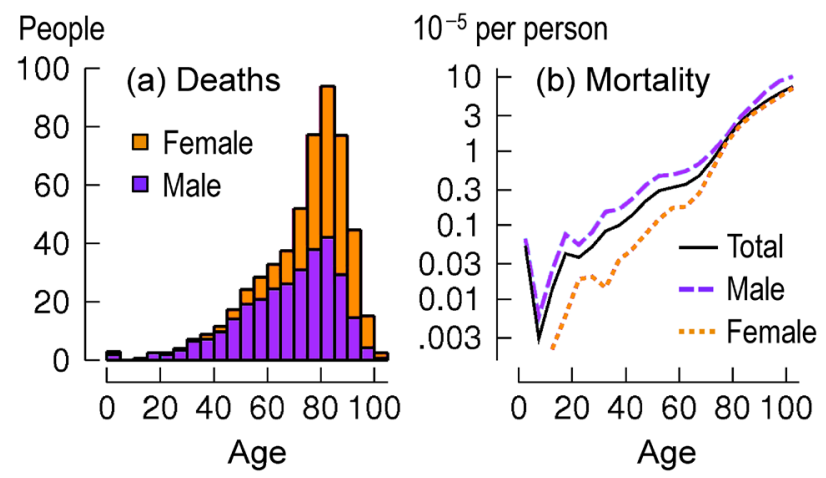

Figure 2. Number of heat-stroke deaths (per year) and mortality rate for five-year age groups. tial dependence on temperature (Nakai et al. 1999; Ono 2003; Asanuma et al. 2007). In the subsequent analysis, mortality is used in logarithm, unless otherwise stated.

The ratio of male to female victims is reversed at around age 75 , whereas the male mortality is higher than female mortality for all age ranges. Therefore, the reversal of the ratio of male/female victims is mainly due to uneven male/female populations at higher ages. However, the difference between male and female mortalities decreases towards higher age. In other words, the difference between male and female mortalities is larger for young and middle-aged individuals than for the elderly.

\section{Temperature}

Hourly temperature data from the network of the Automated Meteorological Data Acquisition System (AMeDAS) of the Japan Meteorological Agency were used. Stations were selected on the condition that days with more than four missing records were at most three in any one of the twelve months of the analyzed 16 years.

For analysis by prefecture, the "temperature of the prefecture" was defined as the average over the stations whose elevation was at most $200 \mathrm{~m}$ above the mean sea level or below the 60th percentile among the stations in the prefecture. This limitation was set because areas with lower elevation tend to be more densely populated, so their averages were likely to be more suitable for the temperatures of the areas in which heat stroke damage occurs. The number of stations in a prefecture ranges from three in Nara to 134 in Hokkaido. To avoid the bias in the presence of missing data for some stations, the average was calculated for the departure from the daily climate normals (see Appendix 1 for definition). In the analysis of a region consisting of more than one prefecture, the temperatures of the prefectures were averaged with a weight of their population from the 2010 census, so that a more populated prefecture could have a larger weight. The latitude of the prefecture was given by averaging the latitude of the AMeDAS stations used for analysis, and that of a region was calculated as a population-weighted average of the latitude of the prefectures in the region, in the same way as for temperature.

In previous studies, several types of temperaturerelated indices have been used for summer heat, including seasonal mean temperature (Fujibe 2013), annual highest daily maximum temperature (Hoshi et al. 2010), and the number of days above a temperature threshold (Takaya et al. 2014). This study is based on two indices: one is the average of daily mean temperatures for July to August $\left(T_{\text {ave }}\right)$, and the other the highest daily maximum 


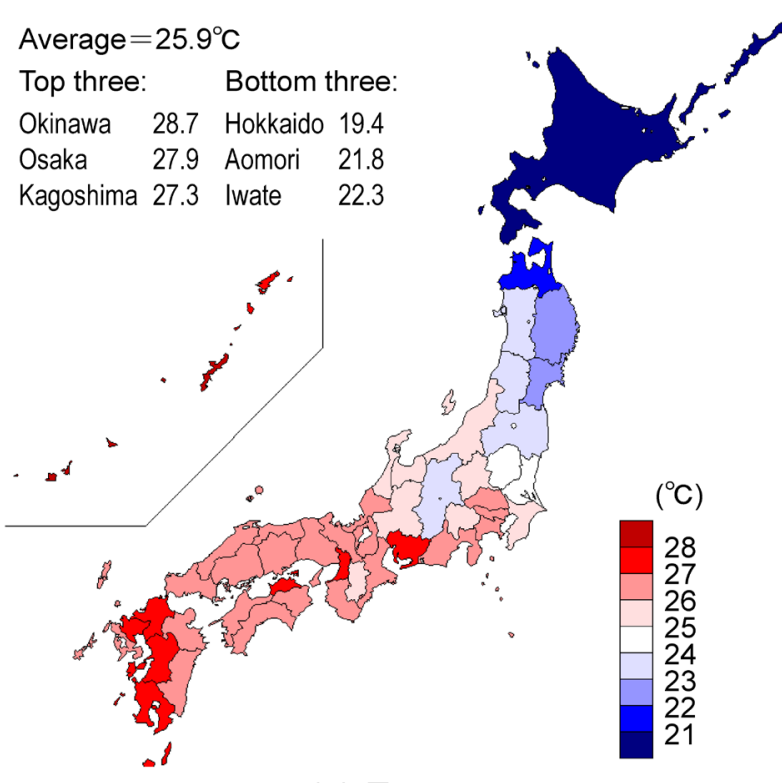

(a) $T_{\text {ave }}$

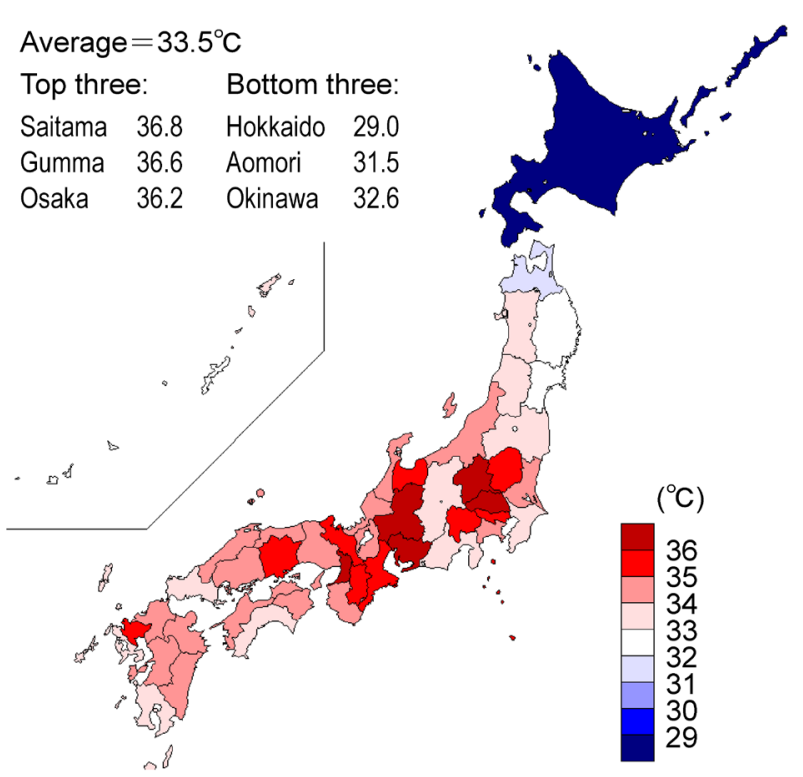

(b) $T_{\max }$

Figure 3. Distribution of (a) $T_{\text {ave }}$ and (b) $T_{\max }$ by average in each prefecture.

temperature of the year $\left(T_{\max }\right)$. They are similar to the indices used by Fujibe (2013) and Hoshi et al. (2010), respectively, apart from the detailed definitions. Figure 3 shows the distribution of $T_{\text {ave }}$ and $T_{\max }$. $T_{\text {ave }}$ tends to increase southward, whereas $T_{\max }$ is high in some of the inland regions of central Honshu.

It is notable that summer in Japan is composed of two periods, Baiu and midsummer (http://www.data.jma. go.jp/gmd/cpd/longfcst/en/tourist_japan.html). The former is characterized by rainy weather, with relatively low temperatures from June to early July, although Baiu starts earlier (May to middle June) in Okinawa and is indistinct in Hokkaido (Maejima 1967; Inoue and Matsumoto 2003). The midsummer from late July to August is the hottest period of the year, characterized by sunny weather, under the dominance of the subtropical high, and is accompanied by numerous heat stroke casualties. The midsummer period is longer in southern regions, where Baiu ends earlier and the autumnal polar airmass arrives later than in northern regions, resulting in higher summer mean temperatures (namely, higher $T_{\text {ave }}$ ). On the other hand, extremely high temperature is more often observed in the inland areas of central Honshu than other regions, being sometimes accompanied by orographically induced foehn and foehn-like winds (Fujibe 2004; Takane and Kusaka 2011), so that $T_{\max }$ is high in some of the regions in central Honshu. In this study, both $T_{\text {ave }}$ and $T_{\max }$ were used in view of their different regional features. The average daily maximum temperature for July to August is not used, but its distribution is more like that of $T_{\text {ave }}$ than $T_{\max }$.

\section{Regional division and correlation calculations}

The regional analysis is based on the indices obtained for each prefecture, as previously described. Their correlation over prefectures was calculated in two ways: one by including the two prefectures of Hokkaido and Okinawa, and the other without them. This is because the two prefectures have highly different climates from others, so the correlation calculated without them is expected to rather represent the features for most of the country, as opposed to including them. In the following, the correlation calculated without the two prefectures will be shown first, with that including them shown between brackets. For example, the correlation between $T_{\text {ave }}$ and $T_{\max }$ in Figure 3 is 0.53 [0.61].

In the analysis of year-to-year variability, there are a number of null data with no deaths in a prefecture over a year, so that the logarithm of mortality is invalid. To avoid this problem, the prefectures were grouped into 14 regions (A to N), as per Figure 1. Similarly, the correlation over regions was calculated for the 12 regions except A and N (Hokkaido and Okinawa), with the value for all the 14 regions shown between brackets. The 13 regions, except Okinawa, were further grouped into three large regions of northern Japan (Regions A-C), eastern Japan (Regions D-H), and western Japan (Regions I-M).

\section{Results}

\section{Spatial patterns}

Figure 4 shows the distribution of mortality for all ages, those below 60 (denoted by "60 y/o" in the figure), and those 80 or over. The last two will be denoted by " $<60$ 


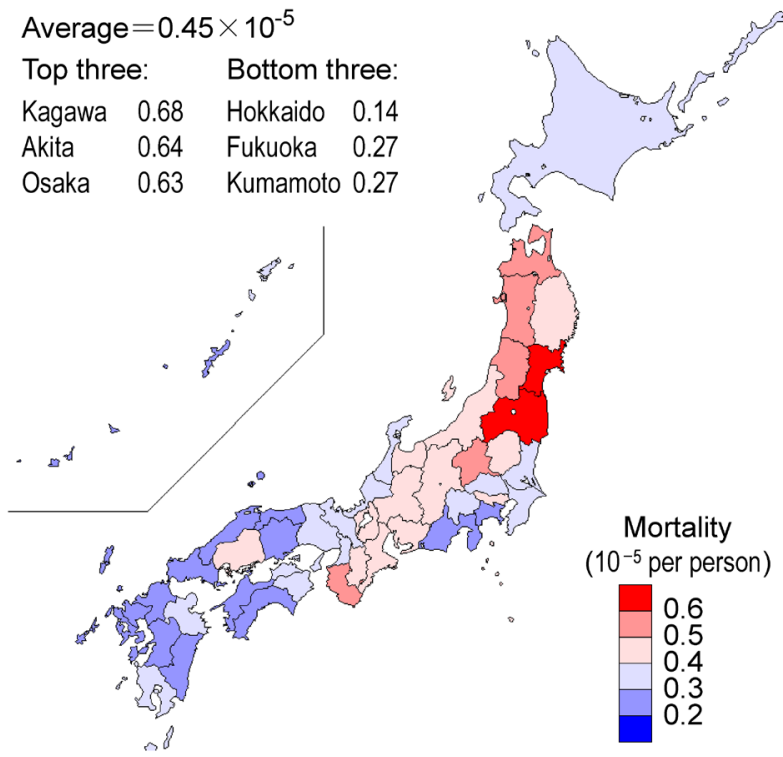

(a) All ages

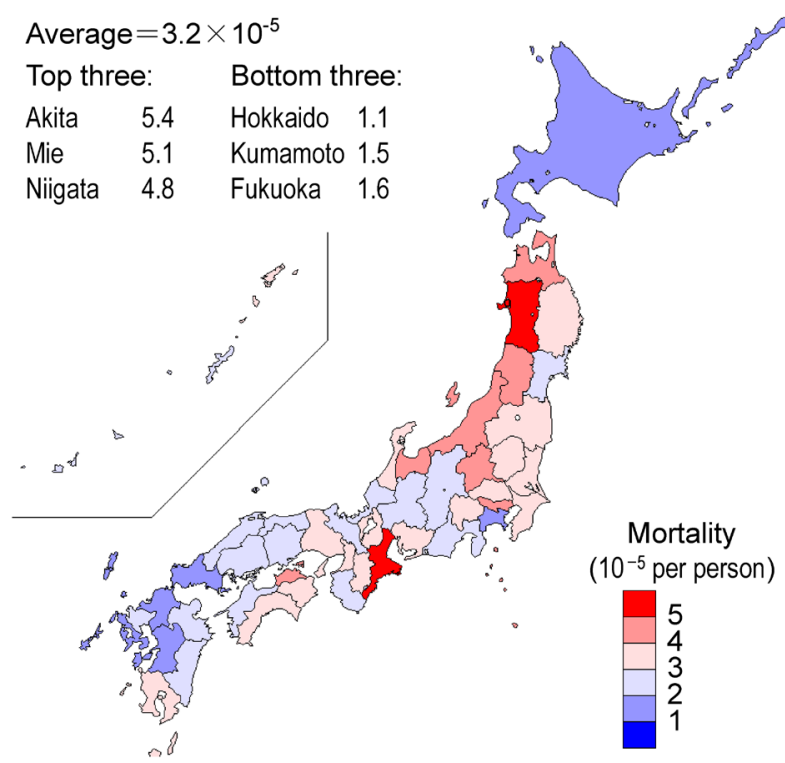

(c) $\geqq 80$ y/o

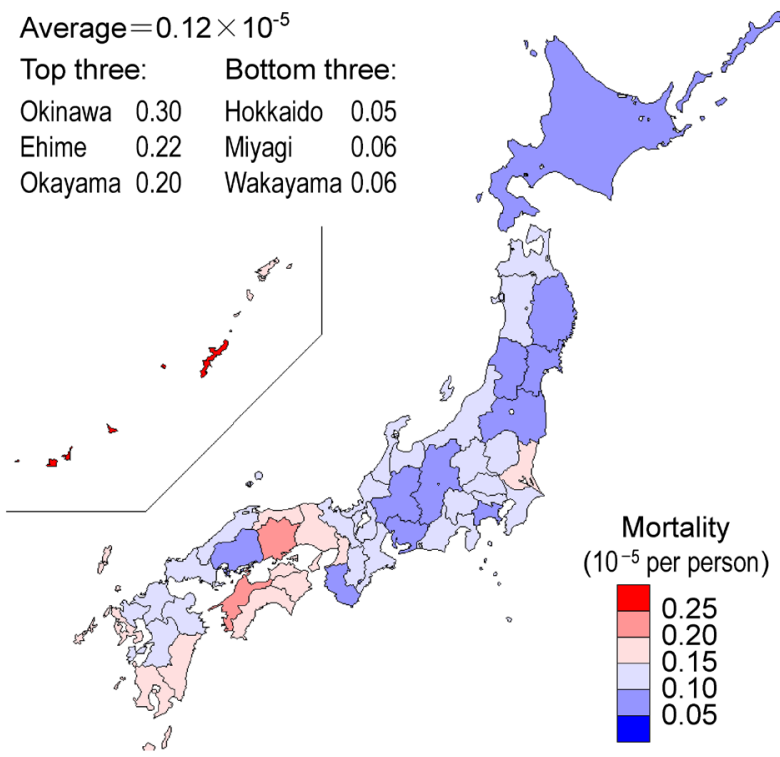

(b) $<60 y / 0$

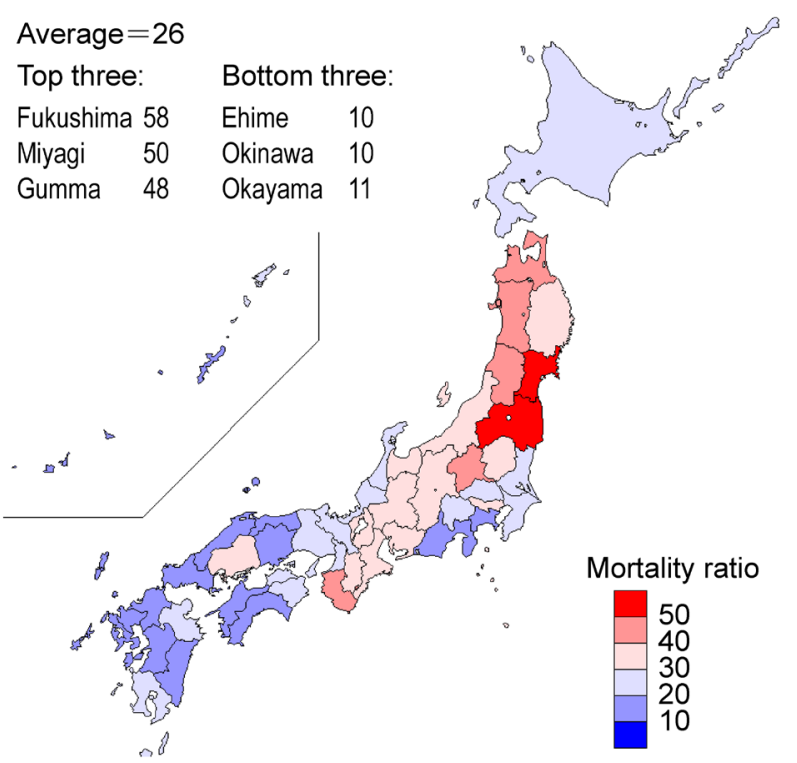

(d) $\geqq 80$ y/o $\div<60$ y/o

Figure 4. Distribution of heat-stroke mortality for (a) all ages, (b) $<60$ group, and (c) $\geq 80$ group, together with (d) the ratio of the $\geq 80$ and $<60$ groups.

group" and " $\geq 80$ group" hereafter. The mortality for all ages is high in some prefectures on the northwestern side of northern to central Honshu (Figure 4-a), and on the southern coast of Honshu to Kyushu, while mortality is lowest in Hokkaido, with a value of about one third the country average.

The distribution of mortality differs by age group. The mortality of the $<60$ group tends to increase southward, with the highest value in Okinawa Prefecture (Figure 4 -b). For the $\geq 80$ group, mortality tends to increase northward, except in Hokkaido (Figure 4-c). The mortality of the $\geq 80$ group is higher than that of the $<60$ group in all the areas, but their ratio (Figure 4-d) differs by a factor of 5-6 between some prefectures from the south- ern and northern regions, respectively. The mortalities of the two age groups are almost uncorrelated spatially, with a coefficient of 0.10 [0.21] for their logarithm and 0.06 [0.09] for raw values.

Figure 5 shows the relation between mortality and $T_{\text {ave }}$ in each prefecture. The values of the correlation coefficients are listed in the upper part of Table 1 . The mortality of the $<60$ group has a positive correlation with $T_{\text {ave }}$, while that of the $\geq 80$ group a negative correlation with $T_{\text {ave }}$ if Hokkaido and Okinawa are excluded. On the other hand, both groups show weak positive correlations with $T_{\max }$, although statistical significance is limited.

In view of the correlation between $T_{\text {ave }}$ and $T_{\max }$, multiple regression analysis was used. The resulting partial cor- 

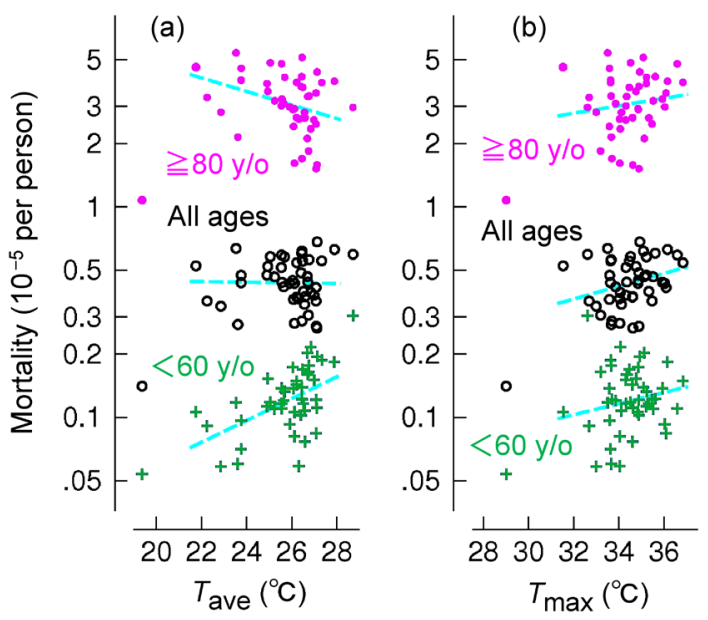

Figure 5. Relationship between mortality in each prefecture and (a) $T_{\text {ave }}$ and (b) $T_{\max }$ for all ages (black open circles), <60 group (green crosses), and $\geq 80$ group (pink dots). The dashed light blue line indicates a linear regression for the 45 prefectures, excluding Hokkaido and Okinawa.

Table 1. Correlation coefficients between temperature $\left(T_{\text {ave }}\right.$ and $\left.T_{\max }\right)$ and mortality over prefectures. Values obtained without Hokkaido and Okinawa are shown, along with those obtained including the two prefectures between brackets

\begin{tabular}{|c|c|c|c|}
\hline & Age group & $T_{\text {ave }}$ & $T_{\max }$ \\
\hline \multirow{3}{*}{ Single correlation } & All ages & $-0.02[\underline{0.33}]$ & $0.29[\underline{\underline{0.48}}]$ \\
\hline & $<60$ & $\underline{\underline{0.51}}[\underline{\underline{0.63}}]$ & $0.20[0.25]$ \\
\hline & $\geq 80$ & $-\underline{0.32}[0.01]$ & $0.13[\underline{0.36}]$ \\
\hline \multirow{3}{*}{ Partial correlation } & All ages & $-0.22[0.05]$ & $\underline{0.36}[\underline{0.38}]$ \\
\hline & $<60$ & $\underline{\underline{0.49}}[\underline{\underline{0.62}}]$ & $-0.10[-0.21]$ \\
\hline & $\geq 80$ & $-\underline{\underline{0.46}}[-0.28]$ & $\underline{0.38}[\underline{\underline{0.44}}]$ \\
\hline
\end{tabular}

Underlines indicate significance at the $\underline{\underline{1 \%}}, \underline{5 \%}$, and $10 \%$ levels.

relation coefficients are shown in the lower part of Table 1. The mortality of the $<60$ group has a positive partial correlation with $T_{\text {ave }}$, but is almost uncorrelated with $T_{\max }$. On the other hand, the mortality of the $\geq 80$ group is positively correlated with $T_{\max }$, and negatively with $T_{\text {ave }}$. The negative partial correlation with $T_{\text {ave }}$ means the mortality tends to be higher in prefectures with lower values of $T_{\text {ave }}$, if $T_{\max }$ values are constant.

Figure 6 shows the partial correlation between mortality and temperature indices for 10 -year age groups. The correlation between mortality and $T_{\text {ave }}$ changes from positive to negative with age, while that between mortality and $T_{\max }$ is higher for those 70 and over than for those in their 50s. Therefore, the dependence of mortality on $T_{\text {ave }}$ and $T_{\max }$ is reversed around age 60 . The results for the age

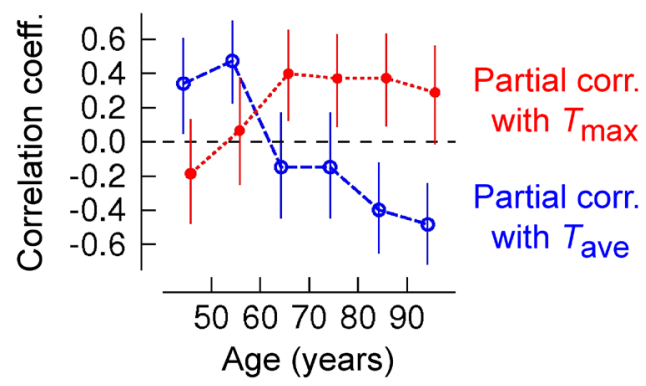

Figure 6. Partial correlation between mortality and temperature $\left(T_{\text {ave }}\right.$ and $\left.T_{\text {max }}\right)$ for $<50$ years old, $\geq 90$ years old, and intermediate ten-year age groups. Vertical bars indicate $95 \%$ confidence ranges.

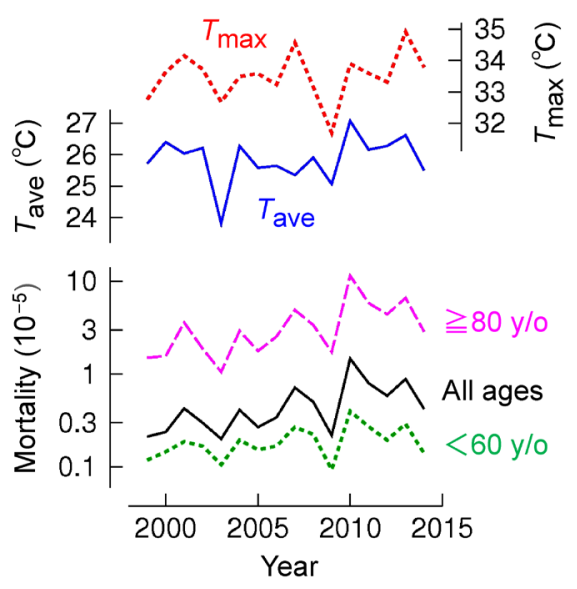

Figure 7. Year-to-year changes in mortality and temperature $\left(T_{\text {ave }}\right.$ and $\left.T_{\max }\right)$ for the entire country.

range 60-80 are not shown here, but have intermediate features compared to the results for the $<60$ and the $\geq 80$ groups, as implied from Figure 6.

\section{Interannual variability}

Figure 7 shows the year-to-year variations of mortality and temperature for the entire country. The mortalities of all ages, $<60$ group, and $\geq 80$ group are almost in phase. The correlation between the annual values of the mortality for the $<60$ and $\geq 80$ groups (in logarithm, as stated before) is as high as 0.93 , by contrast to the low correlation in their spatial distribution. However, the mortality of the $\geq 80$ group tends to show a larger year-to-year variation and a higher increasing trend than the $<60$ group. As for the relationship with temperature, the mortality of all ages is correlated with $T_{\text {ave }}$ and $T_{\max }$ with correlation coefficients of 0.60 and 0.66 , respectively. The mortalities of the $<60$ and $\geq 80$ groups also have correlations of $0.6-0.7$ with $T_{\text {ave }}$ and $T_{\max }$.

Regarding the regional features of the interannual variation, there are some null data for some years, even after grouping prefectures into regions (Figure 1), so that an 
analysis based on the logarithm of mortality is invalidated. As an alternative index of the magnitude of yearto-year mortality variation, the coefficient of variation $(\mathrm{CV})$ is defined as the standard deviation (SD) divided by the mean. The CV of the mortality for the entire country is 0.60 for all ages, 0.39 for the $<60$ group, and 0.64 for the $\geq 80$ group. The ratio of the $\mathrm{CV}$ between the $<60$ and $\geq 80$ groups is significant at the $5 \%$ level ( $p=0.032$ according to the F-test). According to the analysis for each region, the value of $\mathrm{CV}$ for the $\geq 80$ group is larger than that of the $<60$ group in 10 among the 14 regions. This percentage of $10 / 14=0.714$ is significantly higher than $1 / 2$ at the $10 \%$ level. Therefore, the mortality of the elderly tends to show a larger interannual variation than that of young and middle-aged individuals.

Figure 8 shows the $\mathrm{CV}$ of mortality for all ages, and the SDs of $T_{\text {ave }}$ and $T_{\max }$ in each region. The CV of mortality tends to increase northward, with the SD of temperature.

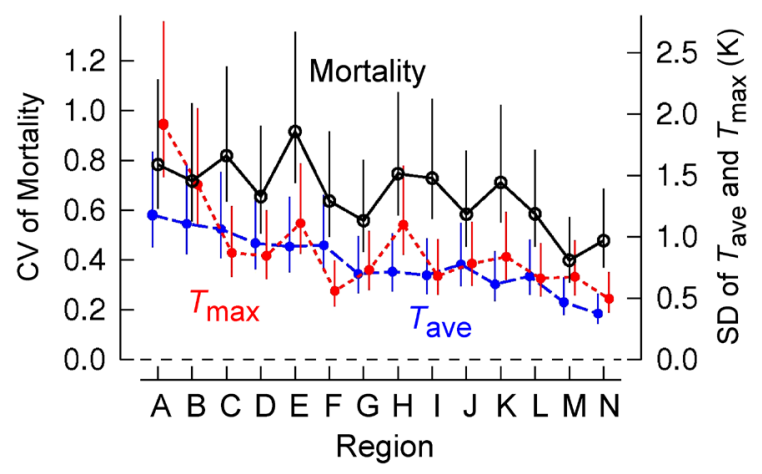

Figure 8. The coefficient of annual variation (CV) of mortality, and standard deviation (SD) of $T_{\text {ave }}$ and $T_{\max }$ for the 14 regions. Vertical bars indicate $95 \%$ confidence ranges.
Table 2 shows the correlation coefficients between the $\mathrm{CV}$ of mortality and SD of temperature by region. The $\mathrm{CV}$ of mortality for all ages is positively correlated with the SD of $T_{\text {ave }}$, significant at the $10 \%$ level if Hokkaido and Okinawa are excluded. A similar feature is found for the $\geq 80$ group. The correlation increases if Hokkaido and Okinawa are included from the calculation, mainly because of the high variabilities of mortality and temperature in Hokkaido. A significant correlation is also found between the $\mathrm{CV}$ of mortality for the $\geq 80$ group and $T_{\max }$, while the correlation is low for the $<60$ group.

Fujibe (2013) evaluated the mortality temperature dependence and long-term trend using the least-squares condition:

$$
\ln M_{\text {in }}=\alpha_{i}+\beta_{i} T_{i n}+\gamma_{i} n+\varepsilon_{i n},
$$

where $T_{\text {in }}$ is either $T_{\text {ave }}$ or $T_{\text {max }}$ in region $i$ and year $n$; $\alpha_{i}$, $\beta_{i}$, and $\gamma_{i}$ are least-squares coefficients; and $\varepsilon_{i n}$ is the error term. The values of $\alpha_{i}, \beta_{i}$, and $\gamma_{i}$ were estimated by a multiple regression analysis that minimizes the squared sum

Table 2. Correlation between the CV of mortality and SD of temperature ( $T_{\text {ave }}$ and $T_{\max }$ ) over the 12 regions, excluding Regions $A$ and $\mathrm{N}$ (Hokkaido and Okinawa). The values obtained including these two regions are between brackets

\begin{tabular}{ccc}
\hline Age group & $T_{\text {ave }}$ & $T_{\max }$ \\
\hline All ages & $\underline{\underline{0.83}}[\underline{\underline{0.87}}]$ & $\underline{0.66}[\underline{0.73}]$ \\
$<60$ & $0.47[\underline{0.56}]$ & $0.00[\underline{0.51}]$ \\
$\geq 80$ & $\underline{0.71}[\underline{0.60}]$ & $\underline{0.69}[\underline{\underline{0.74}}]$ \\
\hline
\end{tabular}

Underlines indicate significance at the $1 \%, 5 \%$, and $10 \%$ levels.

Table 3. List of estimated values for $\beta_{i}$ and $\gamma_{i}$ for the entire area and the three regions

\begin{tabular}{|c|c|c|c|c|c|c|}
\hline & & Age group & Whole country & Northern Japan & Eastern Japan & Western Japan \\
\hline \multirow{6}{*}{$T_{\text {ave }}$} & \multirow{3}{*}{$\beta_{i}\left(K^{-1}\right)$} & All ages & $\underline{\underline{0.43}}$ & $\underline{\underline{0.43}}$ & $\underline{\underline{0.47}}$ & $\underline{\underline{0.52}}$ \\
\hline & & $<60$ & $\underline{\underline{0.34}}$ & 0.18 & $\underline{\underline{0.41}}$ & $\underline{\underline{0.47}}$ \\
\hline & & $\geq 80$ & $\underline{\underline{0.50}}$ & $\underline{\underline{0.44}}$ & $\underline{\underline{0.59}}$ & $\underline{\underline{0.54}}$ \\
\hline & \multirow{3}{*}{$\gamma_{i}\left(\right.$ year $\left.^{-1}\right)$} & All ages & $\underline{\underline{0.067}}$ & 0.019 & $\underline{0.069}$ & $\underline{\underline{0.084}}$ \\
\hline & & $<60$ & 0.032 & 0.017 & 0.036 & 0.026 \\
\hline & & $\geq 80$ & $\underline{0.067}$ & 0.015 & $\underline{0.074}$ & $\underline{\underline{0.098}}$ \\
\hline \multirow{6}{*}{$T_{\max }$} & \multirow{3}{*}{$\beta_{i}\left(\mathrm{~K}^{-1}\right)$} & All ages & $\underline{\underline{0.46}}$ & $\underline{\underline{0.38}}$ & $\underline{\underline{0.51}}$ & $\underline{\underline{0.51}}$ \\
\hline & & $<60$ & $\underline{\underline{0.36}}$ & $\underline{0.24}$ & $\underline{\underline{0.44}}$ & $\underline{0.39}$ \\
\hline & & $\geq 80$ & $\underline{0.49}$ & $\underline{\underline{0.37}}$ & $\underline{\underline{0.56}}$ & $\underline{0.51}$ \\
\hline & \multirow{3}{*}{$\gamma_{i}\left(\right.$ year $\left.^{-1}\right)$} & All ages & $\underline{\underline{0.065}}$ & 0.026 & $\underline{\underline{0.070}}$ & $\underline{\underline{0.080}}$ \\
\hline & & $<60$ & 0.030 & 0.019 & 0.037 & 0.025 \\
\hline & & $\geq 80$ & $\underline{0.066}$ & 0.023 & $\underline{0.077}$ & $\underline{\underline{0.095}}$ \\
\hline
\end{tabular}


of $\varepsilon_{i n}$ over $n$. The temperature dependence is given by $\beta_{i}$, and the trend of mortality is by $\gamma_{i}$. Table 3 shows the values of $\beta_{i}$ and $\gamma_{i}$ estimated by applying the model in Eq. (4) to the entire country and the three large regions, for all ages and the two age groups. For the entire country, the $\beta_{i}$ and $\gamma_{i}$ values are positive and significant at the 1 or $5 \%$ levels. However, $\gamma_{i}$ of the $\geq 80$ group is substantially larger than the value for the $<60$ group. This result indicates a higher increasing rate of the mortality of the elderly over young and middle-aged people, as reported by Fujibe (2013). Additionally, $\beta_{i}$ is slightly higher for the $\geq 80$ group than the $<60$ one. This difference is statistically insignificant, but seems to be consistent with the larger variability of mortality for the $\geq 80$ group (Figure 7). Larger values of $\beta_{i}$ and $\gamma_{i}$ for the $\geq 80$ group than the $<60$ group are commonly found for the three regions.

An alternative analysis was attempted using a model including both $T_{\text {ave }}$ and $T_{\max }$ as

$$
\ln M_{i n}=\alpha+\beta_{1 i} T_{\text {avein }}+\beta_{2 i} T_{\max i n}+\gamma_{i} n+\varepsilon_{i n} .
$$

The analysis resulted in smaller values for $\beta_{1 i}$ and $\beta_{2 i}$ than the $\beta_{i}$ values estimated from Eq. (4). For example, Eq. (5) applied to the entire country results in $\beta_{1 i}=0.26 \mathrm{~K}^{-1}$ and $\beta_{2 i}=0.33 \mathrm{~K}^{-1}$, which are significant at the 10 and $5 \%$ levels, respectively, in contrast to $\beta_{i}=0.41 \mathrm{~K}^{-1}$ for $T_{\text {ave }}$ and $\beta_{i}=0.45 \mathrm{~K}^{-1}$ for $T_{\max }$ according to Eq. (4). The value of $\gamma_{i}$ does not change markedly if Eq. (5) is used instead of Eq. (4).

Figure 9 shows the values of $\beta_{i}$ and $\gamma_{i}$ for each region, with $T_{\text {ave }}$ used for $T_{i n}$. Both $\beta_{i}$ and $\gamma_{i}$ have positive values, significant at the $5 \%$ level in some regions, and $\beta_{i}$ tends to increase southward. The correlation between $\beta_{i}$ and the mean latitude over regions is $-0.57[-0.60]$, which is significant at the $10 \%$ [5\%] level. The larger value for $\beta_{i}$

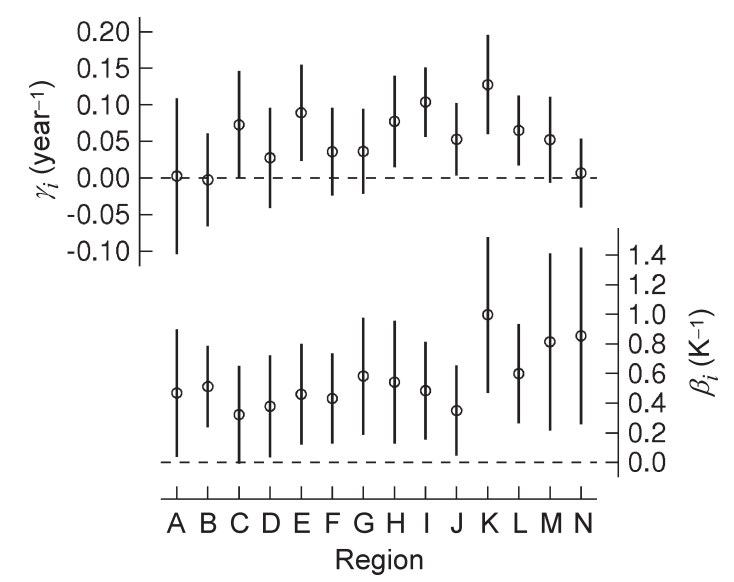

Figure 9. Values of $\beta_{i}$ and $\gamma_{i}$ estimated from the model in Eq. (4) for the 14 regions. Vertical bars indicate $95 \%$ confidence ranges. in the southern regions despite lower interannual variations of mortality (Figure 8) may reflect that the southern regions have lower temperature variations, which makes the variation of mortality relatively higher. An analysis using $T_{\max }$ instead of $T_{\text {ave }}$ yields a similar result, although the correlation between $\beta_{i}$ and latitude is insignificant (unless Hokkaido and Okinawa are included).

\section{Seasonal variations}

Figure 10 shows the mortality for each month from April to November, for the entire country and each of the two regions in the northern part of Japan (A and B) and the southern part of Japan ( $\mathrm{M}$ and $\mathrm{N}$ ), respectively. In all regions except Region N (Okinawa), the mortality in July and August accounts for about $80 \%$ of the total mortality for the year. On the country average, the percentage of mortality in July and August to the annual total is $82 \%$. In Okinawa, as an exception, the contribution of mortality in July and August is only $60 \%$, while that of the four months from June to September is $92 \%$, corresponding to higher heat mortality in June and September than in other regions.

Specifically, mortality has a distinct peak in August in Regions A and B, and in July in regions $\mathrm{M}$ and $\mathrm{N}$. Figure 11-a shows the relationship between latitude and the

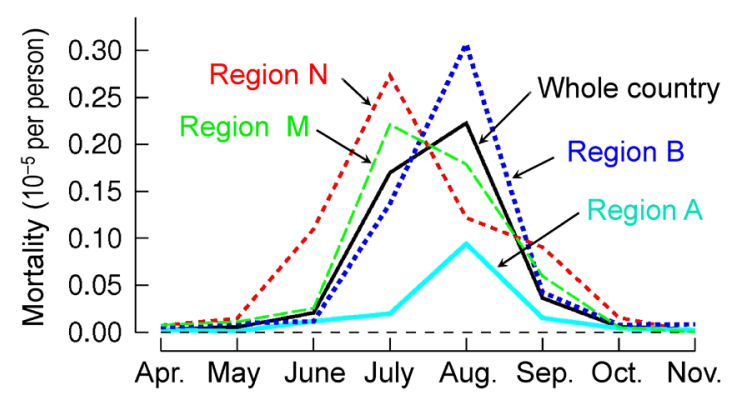

Figure 10. Heat-stroke mortality for each month for the entire country and the four regions.
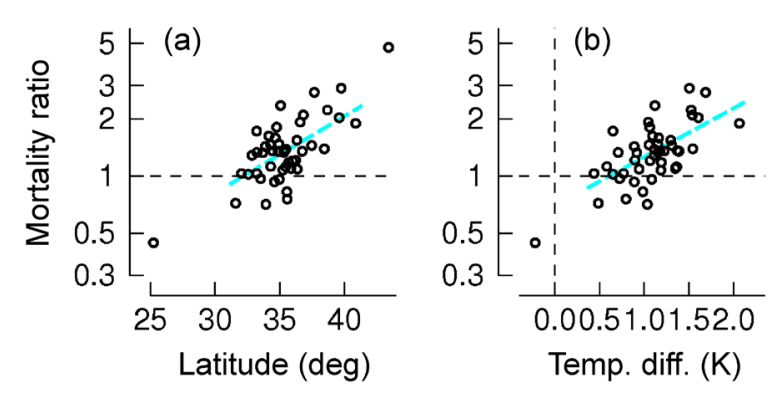

Figure 11. Relationship between August/July mortality ratio and (a) latitude, and (b) August minus July temperature difference for each prefecture. The dashed light blue line indicates a linear regression line, excluding Hokkaido and Okinawa. 
August/July ratio of mortality for each prefecture. The mortality ratio (in logarithm) is correlated with latitude, with a coefficient of 0.57 [0.74], significant at the $1 \%$ level. Figure 11-b shows the relationship between the difference of monthly mean temperatures (August minus July) and mortality ratio. The two quantities have a correlation of 0.60 [0.72], which implies that the peak month of mortality reflects the peak month of seasonal temperature change. It notable that the August minus July temperature difference is strongly correlated with latitude, with a coefficient of 0.85 [0.89].

Interestingly, in Figure 11-b, the data points are deviated to the right of the point of equal temperature and equal mortality, namely the intersection of the horizontal and vertical dotted lines. This indicates that mortality is higher in July than in August if the mean temperatures are equal. The difference is 0.36 [0.51], according to the linear regression in Figure 11-b (gray dashed line). Alternatively, Eq. (4) was applied to each of the two months of July and August in each year, by adding a term indicating the July-August difference as

$$
\ln M_{i n m}=\alpha_{i}+\beta_{i} T_{i n m}+\gamma_{i} n+\delta_{i} S_{m}+\varepsilon_{i n m},
$$

where $m$ is month, and $S_{m} 0.5$ for July and -0.5 for August. The least-squares coefficient $\delta_{i}$, which gives the mortality ratio for July and August, is estimated at 0.35 for the entire country and 0.40 for eastern and western Japan. These values are significant at the 5\% level, although it was impossible to apply Eq. (6) to northern Japan due to null data. The value of $0.35-0.4$ means that mortality in July is higher than in August by a factor of $\exp (0.35-0.4) \approx 1.4-1.5$, if the mean temperature is equal. When applied to the $<60$ and $\geq 80$ groups for the entire country, $\delta_{i}$ values were 0.30 and 0.42 , respectively. The difference between the age groups is not statistically significant, but the $\geq 80$ group may have larger heterogeneity between July and August.

\section{Discussion}

The heat stroke mortality in Japan increases with age, and is higher for men than women. Its year-to-year variation is characterized by a positive trend and positive correlation with temperature, while its seasonal variation has a strong peak from July to August. In the spatial pattern, heat mortality tends to be high in the prefectures on the northwestern side of northern to central Honshu and on the southern coast of Honshu to Kyushu. This study has confirmed these features, which agree with our previous knowledge, including the findings of Hoshi et al. (2010,
2016) and Fujibe (2013). Additionally, this study has provided a number of new findings.

One is represented by the different climatological features of heat mortality by age. The mortality of the $<60$ group is mainly dependent on summer mean temperature $\left(T_{\text {ave }}\right)$, which implies the extent of chance to be exposed to high temperatures. The mortality of the $<60$ group is highest in Okinawa, where the midsummer period is longer than in other regions, corresponding to an earlier end of Baiu and a later arrival of autumnal cold air. On the other hand, the mortality of the $\geq 80$ group is dependent on the peak temperature $\left(T_{\max }\right)$, implying the vulnerability of elderly people to sporadic heat. The negative partial correlation of the mortality of the $\geq 80$ group with $T_{\text {ave }}$ is interpretable as a risk of temporary heat in a relatively cool climate, so that heat stroke deaths occur even in northern Japan, although heat mortality is low in Hokkaido as a result of a much cooler summer climate than in other regions. The large interannual variation of the mortality for the $\geq 80$ group may also reflect the poor adaptability of the elderly to temperature variations.

The different climatology of heat mortality by age indicates the need of different measures for damage prevention. The currently used thermal indices are designed to represent the heat load for outdoor conditions. For example, the wet-bulb globe temperature (WBGT) is a function of insolation and wind speed, which are valid mainly outdoors. However, for the elderly, heat strokes often occur indoors (e.g., Kuzuya 2013), where WBGT may not be the best thermal index.

As for seasonal change, this study revealed a higher mortality in July than in August for an equal mean temperature. This statistically confirms the common view that the hot weather just after the end of Baiu is particularly dangerous and could lead to heat strokes.

A number of studies on urban areas have revealed small-scale variations of heat stroke casualties over time and space, corresponding to day-to-day variations and sub-city distributions of temperature, as well as some social factors (Kurabayashi and Fukuda 2005; Hoshi et al. 2007; Samata et al. 2008; Akatsuka et al. 2016; Fujibe et al. 2017). It is thus important to clarify the details of these small-scale features to take effective measures that mitigate heat damage. The results of this study are expected to provide a climatological background to such efforts.

However, the study has not treated humidity, which is believed to influence the occurrence of heat strokes in addition to temperature. However, Takaya et al. (2014) showed a negative correlation between the interannual variations of WBGT and relative humidity in the Kanto 
area. A high humidity on a seasonal time scale implies the dominance of cloudy and rainy weather, associated with low temperatures, and therefore low WBGT. The relationship between humidity and the risk of heat strokes should be examined in future studies based on analysis on a daily time scale.

\section{Summary}

Using individual data from the Vital Statistics of Japan from 1999 to 2014, the following features were found for heat stroke mortality in Japan.

(1) Spatial patterns: The heat mortality of the $<60$ group tends to be high in the southern part of Japan, while that of the $\geq 80$ group is high in some prefectures on the northwestern side of northern to central Honshu. The mortality of the $<60$ group has a positive correlation with summer mean temperature $\left(T_{\text {ave }}\right)$, while that of the $\geq 80$ group a positive correlation with annual maximum temperature $\left(T_{\max }\right)$ and a negative partial correlation with $T_{\text {ave }}$.

(2) Interannual variation: The magnitude of year-to-year variations in heat mortality tends to increase northward, and so does the magnitude of summer temperature variations. However, the regression coefficient of heat mortality to temperature variation increases southward. The mortality of the $\geq 80$ group tends to show larger interannual variations and larger trend than that of the $<60$ group.

(3) Seasonal features: The peak time of heat mortality delays northward, corresponding to the later peak time of seasonal temperature variation. However, mortality tends to be higher in July than in August by $40-50 \%$, if the monthly mean temperatures are equal.

These findings are expected to provide a statistical basis to cope with heat load disaster in Japan. The different climatological features of heat stroke mortality by age group imply different response to excessive heat loads with age. We hope that our findings can contribute to taking proper measures to prevent heat-stroke deaths.

\section{Acknowledgements}

The study was conducted under the cooperative project "Projection of heat stroke and cold-related risk from climate modeling" by Tokyo Metropolitan University and the Tokyo Medical Examiner's Office. It was financially supported by the Leading Project of Tokyo Metropolitan University (FY 2015-2016), and JSPS KAKENHI (Grant Numbers 26220202 and 17K00523). Data on heat stroke deaths were provided by the Ministry of Health, Labour and Welfare of Japan, with the assistance of the Research Administration Office of Tokyo Metropolitan University.

\section{References}

Akatsuka, S., Uno, T. and Horiuchi, M. 2016. The relationship between the heat disorder incidence rate and heat stress indices at Yamanashi Prefecture in Japan. Advances in Meteorology 2016: 9492815, doi: 10.1155/2016/9492815

Asanuma, S., Liang, C. and Ando, M. 2007. Impact assessment of heat stress on population health in Japan and China. Global Environmental Research 11: 39-44.

Fujibe, F. 2004. Features of extremely high summertime temperatures in Japan in recent years. Geographical Review of Japan 77: 119-132. (JE)

Fujibe, F. 2013. Long-term variations in heat mortality and summer temperature in Japan. Tenki 60: 371-381. (JE)

Fujibe, F., Matsumoto, J. and Suzuki, H. 2017. Relationship between heat mortality and temperature distribution in the Tokyo ward area: Analysis for the 2013 summer. Journal of Heat Island Institute International 12: 1-8. (JE)

Hoshi, A., Inaba, Y. and Murayama, K. 2007. Characteristics of incidence of heat disorders in Tokyo and Chiba-shi. Japanese Journal of Biometeorology 44: 3-11. (J)

Hoshi, A., Nakai, S., Kaneda, E., Yamamoto, T. and Inaba, Y. 2010. Regional characteristics in the death due to heat disorders in Japan. Japanese Journal of Biometeorology 47: 175-184. (JE)

Hoshi, A., Kashimura, O. and Sakate, S. 2016. Heat disorderrelated mortality rates of major Japanese cities. Japanese Journal of Sport and Health Sciences 3: 53-60.

Inoue, T. and Matsumoto, J. 2003. Seasonal and secular variations of sunshine duration and natural seasons in Japan. International Journal of Climatology 23: 1219-1234.

Kurabayashi, T. and Fukuda, A. 2005. Effects of heat island on heatstroke and blooming of trees in Yokohama City. Annual Report of Yokohama Environmental Science Research Institute 29: 92-96. (J)

Kuzuya, M. 2013. Heatstroke in older adults. Japan Medical Association Journal 56: 193-198.

Maejima, I. 1967. Natural seasons and weather singularities in Japan. Geographical Reports of Tokyo Metropolitan University 2: 77-103.

Miyatake, N., Sakano, N. and Murakami, S. 2012. The relation between ambulance transports stratified by heat stroke and air temperature in all 47 prefectures of Japan in August, 2009: ecological study. Environmental Health and Preventive Medicine 17: 77-80.

Murakami, S., Miyatake, N. and Sakano, N. 2012. Changes in air temperature and its relation to ambulance transports due to heat stroke in all 47 prefectures of Japan. Journal of Preventive Medicine and Public Health 45: 309-315.

Nakai, S., Itoh, T. and Morimoto, T. 1999. Deaths from heat-stroke in Japan: 1968-1994. International Journal of Biometeorology 43: $124-127$.

Ono, M. 2003. Heat stroke and the thermal environment. Japan Medical Association Journal 56: 199-205. 
Samata, M., Shirasuna, Y., Inoue, T., Fukuda, A. and Shimomura, K. 2008. Results of atmospheric temperature in summer at 2007 year on Yokohama city and relationship of heatstroke with atmospheric temperature. Annual Report of Yokohama Environmental Science Research Institute 32: 11-14. (J)

Takane, Y. and Kusaka, H. 2011. Formation mechanisms of the extreme high surface air temperature of $40.9^{\circ} \mathrm{C}$ observed in the Tokyo Metropolitan Area: Considerations of dynamic foehn and foehnlike wind. Journal of Applied Meteorology and Climatology 50: 1827-1841.

Takaya, A., Morioka, Y. and Behera, S. K. 2014. Role of climate variability in the heatstroke death rates of Kanto region in Japan. Scientific Reports 4: 5655, doi: 10.1038/srep05655

(J) written in Japanese

(JE) written in Japanese with English abstract

\section{Appendix: Procedure for calculating daily climate normals}

The daily normal provided by JMA is obtained after applying a nine-day running averaging three times to the simple average for 30 years (1981-2010) on each calendar day. The data on February 29 in leap years are not used in this procedure, while the daily normal on February 29 is given by the average of February 28 and March 1.

The daily normals used in this study were obtained in the same way as above, except that the analysis period is 1999-2014. 